OPEN ACCESS

Edited by:

Rena Li,

The Roskamp Institute, United States

Reviewed by:

Giovanni Maconi,

University of Milan, Italy

Yuriko Iwakura,

Niigata University, Japan

${ }^{*}$ Correspondence:

Martina Barrenschee

m.barrenschee@anat.uni-kiel.de; m.barrenschee@gmx.de

Specialty section:

This article was submitted to

Cellular Neuropathology,

a section of the journal

Frontiers in Cellular Neuroscience

Received: 09 July 2019 Accepted: 05 December 2019

Published: 19 December 2019

Citation:

Barrenschee M, Cossais F, Böttner M, Egberts J-H, Becker T and Wedel T (2019) Impaired Expression of Neuregulin 1 and Nicotinic Acetylcholine Receptor $\beta 4$ Subunit in Diverticular Disease.

Front. Cell. Neurosci. 13:563. doi: 10.3389/fncel.2019.00563

\section{Impaired Expression of Neuregulin 1 and Nicotinic Acetylcholine Receptor B4 Subunit in Diverticular Disease}

\author{
Martina Barrenschee ${ }^{1 *}$, François Cossais ${ }^{1}$, Martina Böttner $^{1}$, Jan-Hendrik Egberts ${ }^{2}$, \\ Thomas Becker ${ }^{2}$ and Thilo Wedel ${ }^{1}$
}

\begin{abstract}
${ }^{1}$ Neurogastroenterology, Institute of Anatomy, Christian-Albrechts University of Kiel, Kiel, Germany, ${ }^{2}$ Department of General, Visceral-, Thoracic-, Transplantation-, and Pediatric Surgery, University Hospital Schleswig-Holstein, Kiel, Germany
\end{abstract}

Neuregulin 1 (NRG1) regulates the expression of the nicotinic acetylcholine receptor (nAChR) and is suggested to promote the survival and maintenance of the enteric nervous system (ENS), since deficiency of its corresponding receptor complex ErbB2/ErbB3 leads to postnatal colonic aganglionosis. As diverticular disease (DD) is associated with intestinal hypoganglionosis, the NRG1-ErbB2/ErbB3 system and the nAChR were studied in patients with DD and controls. Samples of tunica muscularis of the sigmoid colon from patients with $\mathrm{DD}(n=8)$ and controls $(n=11)$ were assessed for mRNA expression of NRG1, ErbB2, and ErbB3 and the nAChR subunits $\alpha 3, \alpha 5$, $\alpha 7, \beta 2$, and $\beta 4$. Site-specific gene expression levels of the NRG1-ErbB2/3 system were determined in myenteric ganglia harvested by laser microdissection (LMD). Localization studies were performed by immunohistochemistry for the NRG1-ErbB2/3 system and $n A C h R$ subunit $\beta 4$. Rat enteric nerve cell cultures were stimulated with NRG1 or glial-cell line derived neurotrophic factor (GDNF) for 6 days and mRNA expression of the aforementioned nAchR was measured. NRG1, ErbB3, and nAChR subunit $\beta 4$ expression was significantly down-regulated in both the tunica muscularis and myenteric ganglia of patients with DD compared to controls, whereas mRNA expression of ErbB3 and $\mathrm{nAChR}$ subunits $\beta 2, \alpha 3, \alpha 5$, and $\alpha 7$ remained unaltered. NRG1, ErbB3, and $n A C h R$ subunit $\beta 4$ immunoreactive signals were reduced in neuronal somata and the neuropil of myenteric ganglia from patients with DD compared to control. nAChR subunit $\beta 4$ exhibited also weaker immunoreactive signals in the tunica muscularis of patients with DD. NRG1 treatment but not GDNF treatment of enteric nerve cell cultures significantly enhanced mRNA expression of $n A c h R \beta 4$. The down-regulation of NRG1 and ErbB3 in myenteric ganglia of patients with DD supports the hypothesis that intestinal hypoganglionosis observed in DD may be attributed to a lack of neurotrophic factors. Regulation of $n A C h R$ subunit $\beta 4$ by NRG1 and decreased nAChR $\beta 4$ in patients with DD provide evidence that a lack of NRG1 may affect the composition of enteric neurotransmitter receptor subunits thus contributing to the intestinal motility disorders previously reported in DD.

\footnotetext{
Keywords: NRG1, HRG 1 beta, nAchR, enteric nervous system, diverticular disease, ErbB2, ErbB3
} 


\section{INTRODUCTION}

Diverticular disease (DD) is one of the most common diseases in western countries with high prevalence especially in the elderly. It is characterized by multiple mucosal/submucosal herniations (pseudo-diverticula) through the colonic muscle coat which can lead to a broad spectrum of symptoms with potentially lethal complications (Jun and Stollman, 2002). Despite the considerable burden of DD on the healthcare system (Sandler et al., 2002), the pathogenesis of DD is still discussed controversially and appears to be multifactorial. Increasing age, low-fiber diet, and connective tissue alterations are considered traditionally as risk factors for the formation of colonic diverticula (Strate et al., 2009; Böttner and Wedel, 2012). Moreover, previous reports have given evidence for an underlying enteric neuropathy in DD characterized by a decrease of myenteric nerve cells (oligoneuronal hypoganglionosis) and reduced nerve fibers within smooth muscle layers (Golder et al., 2003; Iwase et al., 2005; Deduchovas et al., 2008; Wedel et al., 2010). It is postulated that the disturbed innervation gives rise to colonic motility disorders frequently reported in DD (Bassotti et al., 2001) thereby promoting the development of diverticula.

Although a loss of enteric neurons represents a common histopathologic phenotype within the spectrum of gastrointestinal neuromuscular pathology (Knowles et al., 2010), the pathomechanisms leading to the reduced ganglionic nerve cell content observed in DD remain unclear. Moreover, the underlying cellular and molecular mechanisms leading to DD are largely unknown (Simpson and Spiller, 2002). However, since $\mathrm{DD}$ is associated with a lack of glial-cell line derived neurotrophic factor (GDNF) and its corresponding receptors (Böttner et al., 2013), a general involvement of neurotrophic factors may play a role in the pathogenesis of DD, e.g., a deficient GDNF system could be a primary trigger for the reduced neuronal number shown in DD (Barrenschee et al., 2017).

Neuregulin 1 (NRG1) belongs to a family of growth factors that contain an epidermal growth factor domain and activates the ErbB2/ErbB3 tyrosine kinases in neural crest cells (Britsch et al., 1998; Garratt et al., 2000). NRG1 is crucial for various functions in the nervous system, e.g., nerve cell differentiation, neurite outgrowth, and synapse formation (Falls, 2003; Mei and Nave, 2014). Isoforms of the neuregulin 1 gene can be classified into three groups (type I-III) (Falls, 2003), where type I isoforms [neu differentiation factor (NDF); heregulin (HRG); acetylcholine receptor inducing activity (ARIA)] have been implicated in neuromuscular junction formation by stimulating muscular nicotinic acetylcholine receptor (nAChR) expression during development (Martinou et al., 1991; Falls et al., 1993).

The importance of NRG1 and its receptor signaling system ErbB2/ErbB3 in the enteric nervous system (ENS) became evident, when NRG1 or its corresponding receptors were ablated in animals. Immunoglobulin-like-NRG1 deficient mice were found to show approximately 50\% reduction in the number of AChRs at neuromuscular synapses and reduced synaptic strength (Sandrock et al., 1997). Additionally, ErbB3-/mice exhibited a total loss of enteric glia and reduced ganglionic number in the duodenum (Erickson et al., 1997;
Riethmacher et al., 1997), and enteric neurons and glial cells were dramatically reduced in conditional ErbB2/Nestin-Cre mutant mice displaying an Hirschsprung's disease-like phenotype (Crone et al., 2003). Recently, we could demonstrate that NRG1 acts as a neurotrophic factor for the ENS, since it promotes the growth and differentiation of postnatal enteric neurons (Barrenschee et al., 2015).

Excitatory nicotinic cholinergic transmission is essential for the regulation of gastrointestinal motility and mediated by neuronal nAChRs in the ENS (Galligan and North, 2004). nAChRs are ligand-gated pentameric ion channels found both in the central and peripheral nervous systems composed of various combinations of alpha and non-alpha subunits (Sargent, 1993; Dani and Bertrand, 2007) resulting in specific nAChR subtypes. In the mammalian nervous system, eight ligand binding $\alpha(\alpha 2-\alpha 7, \alpha 9-\alpha 10)$ and three structural $\beta(\beta 2-\beta 4)$ subunits have been identified. Neuronal nAChRs are widely expressed in the central and peripheral nervous systems in adults and during development (Albuquerque et al., 2009). Whereas in the central nervous system the majority of $\mathrm{nAChRs}$ are either heteromeric $\alpha 4 \beta 2$ containing $\mathrm{nAChRs}$ or homomeric $\alpha 7 \mathrm{nAChRs}$, in the peripheral nervous system heteromeric $\alpha 3 \beta 4$-type nAChRs with or without $\alpha 5$ are the predominant receptors (Mao et al., 2006). Although the expression of nAChRs in the ENS is less well established, it is known that enteric neurons contain $\alpha 3, \alpha 5, \alpha 7$, $\beta 2$, and $\beta 4$ subunit proteins which form different heteromeric nAChR subtypes (Obaid et al., 2005; Grundy and Schemann, 2006; Mandl and Kiss, 2007). In the peripheral nervous system, a3ß4-type nAChRs are considered to represent the predominant receptors (Galligan and North, 2004).

Since DD is associated with a partial loss of enteric neurons and a lack of the nerve growth factor GDNF with concomitant intestinal motility disturbances, we raised the question whether the NRG1 growth factor system and the enteric nAchR subunit composition are also altered in $\mathrm{DD}$, thereby contributing to the intestinal hypoganglionosis and motility dysfunctions in DD.

\section{MATERIALS AND METHODS}

\section{Patients Control Group}

Segments of sigmoid colon were obtained from patients ( $n=10$, four females, six males, mean age: 69.0 years) who underwent anterior rectal resection or left hemicolectomy for non-obstructive colorectal carcinoma. Anorectal evacuation and colonic motility disorders were previously excluded. None of the patients showed colonic diverticula. Full-thickness specimens were harvested from the sigmoid colon at safe distance $(>5 \mathrm{~cm})$ from the tumor.

\section{Patients With DD}

Segments of sigmoid colon were obtained from patients $(n=8$, two females, six males, mean age: 62.0 years) who underwent sigmoid resection or left hemicolectomy for symptomatic DD (e.g., left-sided abdominal pain, meteorism, altered bowel habits). Patients were operated by elective surgery during symptom-free 
interval after two or more episodes of diverticulitis. Time between last episode and surgery ranged from 4 weeks to several months. Two patients showed non-obstructing stenotic narrowing of the sigmoid colon and one patient a covered perforation with paracolic abscess. Patients with emergency surgery for peritonitis due to open perforation or with complications due to obstructed stenosis and fistula formation have been excluded from the study. Full-thickness specimens were harvested from sites at a distance $>1 \mathrm{~cm}$ from diverticula. Diverticula-containing areas displaying an altered anatomy of the colonic wall due to transmural mucosal herniation or fibrotic/inflammatory processes were excluded from tissue sampling. The study of human tissue received approval from the Local Ethics Committee of the Faculty of Medicine, Christian-Albrechts University of Kiel, Germany (B299/07).

\section{Tissue Preparation}

\section{Tissue Processing for mRNA Expression Profiles of the Tunica Muscularis and LMD Samples}

The tunica muscularis was isolated from full-thickness biopsies of the colonic wall, immediately frozen in isopentane and stored at $-70^{\circ} \mathrm{C}$ until use. Prior to RNA isolation 20 orthogonal cryosections $(10 \mu \mathrm{m})$ were cut on a cryostat and collected in RNA lysis buffer (Macherey and Nagel, Düren, Germany). For isolation of myenteric ganglia orthogonal cryosections $(10 \mu \mathrm{m})$ from full-thickness biopsies were placed on membrane-coated (polyethylene naphtalate, $1.0 \mu \mathrm{m}$, Zeiss, Göttingen, Germany) slides. To visualize myenteric ganglia sections were ultra-rapidly (ca. $60 \mathrm{~s}$ ) stained with toluidine blue and air-dried.

\section{Tissue Processing for Immunohistochemical Studies}

After surgical removal, all specimens were transferred into phosphate-buffered saline (PBS) ( $\mathrm{pH} 7.2$ ) at $37^{\circ} \mathrm{C}$ to allow adaption and further dissection. Full-thickness rectangular tissue blocks ( $30 \mathrm{~mm} \times 10 \mathrm{~mm}$ ) were pinned out flat on a cork plate by fine needles without artificial stretching nor shortening, thereby preserving the original size. The longer border of the tissue block was orientated perpendicular to the gut axis and corresponded to the cutting surface for histologic sections, so that myocytes of the circular muscle layer were cut along their longitudinal axis. After fixation (4\% paraformaldehyde in PBS) for $24 \mathrm{~h}$ and dehydration tissue blocks were transferred into paraffin wax and cut in sections $(6 \mu \mathrm{m})$ for immunohistochemistry.

\section{Laser Microdissection and Pressure Catapulting}

Laser microdissection (LMD) was performed by a modified method described previously (Böttner et al., 2010). Briefly, myenteric ganglia and smooth muscle cells of the tunica muscularis were identified by inverse light microscopy (Zeiss Axio Observer Z1, Zeiss, Göttingen, Germany), excised by LMD, and collected by laser pressure catapulting (PALM MicroLaser System, Zeiss, Göttingen, Germany) in caps of $0.5 \mathrm{~mL}$ reaction tubes. Ganglionic and smooth muscle tissue areas of $2 \mathrm{~mm}^{2}$ per specimen were collected, immediately dissolved in $350 \mu \mathrm{L}$ RNA lysis buffer (Macherey and Nagel, Düren, Germany), and stored at $-70^{\circ} \mathrm{C}$ until further use.

\section{RNA Extraction and Reverse Transcription}

Extraction of total RNA from human tissue was performed using a Nucleospin II kit (Macherey and Nagel, Düren, Germany); RNA from enteric nerve cell cultures was isolated using a Nucleospin XS kit (Macherey and Nagel, Düren, Germany) according to the manufacturer's guidelines. Prior to reverse transcription, contaminating genomic DNA was digested in a volume of $15 \mu \mathrm{L}$ using $1.5 \mathrm{U}$ of DNAse I (Sigma, Munich, Germany). Reverse transcription was carried out in a total volume of $30 \mu \mathrm{L}$ containing $200 \mathrm{ng}$ RNA, $375 \mathrm{ng}$ random hexamer primer (GE Healthcare, Freiburg, Germany), $0.5 \mathrm{mM}$ dNTPs (Promega, Mannheim, Germany), 0.01 M DTT, 1× reaction buffer, and $150 \mathrm{U}$ Superscript II Reverse Transcriptase (Invitrogen, Karlsruhe, Germany). The annealing, elongation, and denaturation steps were carried out at $25^{\circ} \mathrm{C}$ for $10 \mathrm{~min}$, at $42^{\circ} \mathrm{C}$ for $50 \mathrm{~min}$, and at $70^{\circ} \mathrm{C}$ for $15 \mathrm{~min}$, respectively.

\section{Quantitative PCR}

Quantitative PCR (qPCR) reactions were run on an ABI Prism 7700 Sequence Detection System (TaqMan, Applied Biosystems, Foster City, CA, United States). Amplification reactions were carried out in a $20 \mu \mathrm{L}$ volume containing $1 \times$ qPCR Master Mix Plus (Eurogentec, Cologne, Germany), 900 nM primers, $225 \mathrm{nM}$ hybridization probe, and $2 \mu \mathrm{L}$ cDNA. Samples were run in duplicate and amplified over 45 cycles. Each cycle consisted of a denaturation phase of $15 \mathrm{~s}$ at $95^{\circ} \mathrm{C}$ and a hybridization/elongation phase of $1 \mathrm{~min}$ at $60^{\circ} \mathrm{C}$. mRNA expression profiles were measured for NRG1, ErbB2, ErbB3, nAchRb2, nAchRb4, nAchRa3, nAchRa5, nAchRa7, and the housekeeping gene HPRT in human samples, and for nAchRb2, nAchRb4, nAchRa3, nAchRa5, nAchRa7, and hprt in rat enteric cell cultures. Forward and reverse primers and probes are listed below.

\section{Primers Amplifying Human Sequences}

NRG1 type I HRGß1 (NM_013956.3): forward primer: 5' atggaggcggaggagctgta- $3^{\prime}$, reverse primer: $5^{\prime}$-ttgcagtaggccaccacaca3', probe: 5'-tgaccataaccggcatctgcatcgc-3'; ErbB2 (NM_004448.2): forward primer: $5^{\prime}$-ggaagtacacgatgcggagact- $3^{\prime}$, reverse primer: $5^{\prime}$ tctctttcaggatccgcatctg- $3^{\prime}$, probe: $5^{\prime}$-tggagccgctgacacctagcgga- $3^{\prime}$; ErbB3 (NM_001982.3): forward primer: 5'-tgccatcttcgtcatgttgaac3', reverse primer: 5'-tcaatataaacacccctgacagaa-3', probe: $5^{\prime}$-agctccgcttgactcagctcaccga; $n A c h R b 2$ (NM_000748), forward primer: 5'-tgaggcgataatcttccactc-3', reverse primer: $5^{\prime}$-gcttatgg tgtcactggccc-3', probe: $5^{\prime}$-tcagtgtgcatgagcgggagcaga-3', nAchRb4 (NM_000750) forward primer: $5^{\prime}$-caaccagatgcgctttgca-3', reverse primer: $5^{\prime}$-tctggctgaaacaggaatgga-3', probe: $5^{\prime}$-cctggaaca gctcccgctacgaggg-3', nAchRa3 (NM_000743): forward primer $5^{\prime}$-ccgacatcacatactcgctgtaca-3': reverse primer: 5'-gacgagcacag tgaggaagga-3', probe: 5'-ccggcgcctgcccttgttctaca-3', nAchRa5 (NM_000745): forward primer: 5'-aaccgtcttcgctatcaacattca-3', reverse primer: $5^{\prime}$-gcagtttgggaagcgtgtga-3', probe: $5^{\prime}$-catggcgccttt ggtccgcaag-3', nAchRa7 (NM_000746): forward primer: 5'-agaa tgggacctagtgggaatcc-3', reverse primer: $5^{\prime}$-ggcgcatggtcactgtgaa-3', probe: 5'-tgctgcaaagagccctaccccgatg-3', HPRT (NM_000194.2, house-keeping gene): forward primer: 5'-tgaacgtcttgctcga 
gatgtg-3', reverse primer: $5^{\prime}$-ccagcaggtcagcaaagaattt-3', probe: $5^{\prime}$-tgggaggccatcacattgtagcc- $3^{\prime}$.

\section{Primers Amplifying Rat Sequences}

NRG1 type I HRG $\beta 1$ (AY973244.1) forward primer: 5'-ctac cagaagagggtgctgacaa-3', reverse primer: $5^{\prime}$-gccgctgcttcttggtttt-3', probe: $5^{\prime}$-ctgctggtggtcggcatcttgtgtg-3'; ErbB2 (NM_017003.2): forward primer: $5^{\prime}$-gctgctgcaggaaactgagttag- $3^{\prime}$, reverse primer: $5^{\prime}$-ccttccttagctccgtctcttttag- $3^{\prime}$, probe: $5^{\prime}$-ctgacgcccagcggagcaatgc- $3^{\prime}$; ErbB3 (XM_006240755.1) forward primer: 5'-cgaggagatgcgag ctttcc-3', reverse primer: 5'-aaagcctgctgtgccagtaatc- $3^{\prime}$, probe: $5^{\prime}$-ccccatgttcgttatgccogct; nAchRb2 (NM_019297.1), forward primer: $5^{\prime}$-cattcgtcgcaaaccactcttc- $3^{\prime}$, reverse primer: $5^{\prime}$-ccacagt ctgagggcaggtaga- $3^{\prime}$, probe $5^{\prime}$-ctgcgtactcatcacctcgctggcc- $3^{\prime}, n A c h R b 4$ (NM_052806.2) forward primer: 5'-atggtgcccagaatacacacaaa-3', reverse primer: 5'-gaccgagatcaaagtgtcatcga-3', probe: 5'-agttc gtcgcgatggttgttgaccg-3', nAchRa3 (NM_052805.2): forward primer $5^{\prime}$-attggaagtacgttgccatggt-3': reverse primer: $5^{\prime}$-gccatcaag ggttgcagaaa-3', probe: 5'-tggtgtgcattttaggaacggcggg-3', nAchRa5 (NM_017078.2): forward primer: 5' -gcacgaaaacagttgtcaggtaca-3', reverse primer: $5^{\prime}$-gatcaaacgggaaaaaggtaacg- $3^{\prime}$, probe: $5^{\prime}$-ctgtc acgtggacgcaaccagcaaa-3', nAchRa7 (NM_012832.3): forward primer: $5^{\prime}$-atgccacgttccacaccaat- $3^{\prime}$, reverse primer: $5^{\prime}$-ccagcgaa cgtcaatgtagca-3', probe: 5'-tctcctccaggcatattcaagagc- $3^{\prime}$, hprt (NM_012583.2, house-keeping gene): forward primer: $5^{\prime}$-cgccag cttcctcctcaga-3', reverse primer: $5^{\prime}$-ggtcataacctggttcatcact- $3^{\prime}$, probe: $5^{\prime}$-ttttcccgcgagccgaccgg-3'.

\section{Enteric Nerve Cell Cultures}

Preparation of myenteric nerve cells was performed according to a method described previously (Schäfer et al., 1997). Briefly, after removing the small intestine from newborn Wistar rats (postnatal day 2-3), the tunica muscularis was stripped from the mucosa, followed by incubation for $2 \mathrm{~h}$ at $37^{\circ} \mathrm{C}$ in $\mathrm{Ca}^{2+}$ - and $\mathrm{Mg}^{2+}$-free Hanks' Balanced Salt Solution (HBSS, Gibco Life Technologies/Invitrogen, Karlsruhe, Germany) with antibiotics containing $1 \mathrm{mg} / \mathrm{mL}$ collagenase (Sigma, Munich, Germany). Afterward, fragments of myenteric plexus were collected under stereomicroscopic control and incubated for $15 \mathrm{~min}$ at $37^{\circ} \mathrm{C}$ in trypsin/EDTA $(0.125 \mathrm{mg} / \mathrm{mL}$ Gibco, Life Technologies, Germany) to dissociate the plexus. The procedure was stopped by replacing trypsin/EDTA with fetal calf serum (FCS, Gibco, Life Technologies/Invitrogen, Karlsruhe, Germany). The cells were triturated, counted, and seeded at a density of 100,000 cells/mL on poly-D-Lysin-(Sigma)/Laminin-(Sigma, Munich, Germany) coated coverslips for immunocytochemistry studies or 12-well-plates for gene expression studies. Cells were incubated in defined medium consisting of Neurobasal A (Gibco, Life Technologies/Invitrogen, Karlsruhe, Germany) and B27 supplement (Gibco, Life Technologies/Invitrogen, Karlsruhe, Germany). Additionally, recombinant human NRG1$\beta 1$ (Thr176-Lys246, EGF Domain) (R\&D Systems, Minnesota, $\mathrm{MN}$, United States) or recombinant rat GDNF (Peprotech, Hamburg, Germany) was added to a final concentration of 0 (control), 2, or $10 \mathrm{ng} / \mathrm{mL}$ for NRG1- $\beta 1$ or $50 \mathrm{ng} / \mathrm{mL}$ for GDNF. Cells were cultured for 1 week and medium was changed every second day.

\section{Immunohistochemistry}

Immunoreactive signals were visualized using the avidinbiotin complex system (Vectastain Elite ABC Kit, Vector Laboratories, Burlingame, CA, United States). Briefly, paraffinembedded tissue sections were incubated with $3 \%$ hydrogen peroxide to block endogenous peroxidase activity, rinsed in TBS-buffer (TRIS-buffered saline; $10 \mathrm{mM}$ TRIS, $50 \mathrm{mM}$ $\mathrm{NaCl}, \mathrm{pH}$ 7.4), and pretreated with citrate buffer ( $\mathrm{pH} 6.0$, $95^{\circ} \mathrm{C}$ water bath, $20 \mathrm{~min}$ for ErbB2 and ErbB3, microwave, $2 \times 750 \mathrm{~nm}, 5 \mathrm{~min}$ for $\mathrm{nAchR} \beta 4$ ). Thereafter, samples were incubated overnight with a polyclonal rabbit-anti-NRG1 $\beta 1$ antibody (HRG $\beta 1,1: 500^{1}$, Aachen, Germany; immunogen sequence: KKPGKSELRINKAS), polyclonal rabbit-anti-ErbB2 antibody $\left(1: 1000^{1}\right.$, Aachen, Germany), polyclonal rabbit-antiErbB3 antibody $\left(1: 2000^{1}\right.$, Aachen, Germany), or polyclonal goat-anti-nAChR $\beta 4$ antibody (1:500 abcam, Cambridge, Germany; immunogen sequence: DYRLTWNSSRYEGVN), diluted in antibody diluent (Invitrogen, Karlsruhe, Germany), and incubated for $45 \mathrm{~min}$ with biotinylated goat anti-rabbit IgG (1:400, DAKO, Hamburg, Germany). After washing three times with TBS, sections were incubated for 45 min with an avidin-biotin complex (Vectastain ABC Standard, Vector Laboratories, Burlingame, CA, United States) conjugated with horseradish peroxidase. 3, 3'-diaminobenzidine (DAKO, Hamburg, Germany) was used as substrate chromogen. Sections were counterstained with Meyer's hematoxylin. Omission of the primary or secondary antibody served as negative controls. Analysis was carried out with a light optical microscope (Nikon 6000, Nikon, Tokyo, Japan) coupled to a digital camera (Digital Sight, Nikon, Tokyo, Japan). Data acquisition was performed with NIS-Elements BR 3.2 software (Nikon, Tokyo, Japan).

\section{Quantitation of Immunofluorescence Signals}

Image acquisition, processing, and analysis were performed as previously described (Barrenschee et al., 2017). Briefly, fluorescence immunohistochemical signals of myenteric ganglia $(n=8)$ were recorded in specimens of controls and patients with DD. Recordings were repeated for each myenteric ganglion in a corresponding blank specimen after omission of the primary antibody maintaining the same settings (e.g., magnification, exposure time for antibodies, DAPI staining). All recordings were performed using a light microscope (Axiovert $200 \mathrm{M}$, Zeiss, Germany) coupled to a digital camera [AxioCam MR3 (monochrome), Zeiss, Germany]. Axiovision (version 4.7, Zeiss, Germany) was used for displaying, managing, and storing the pictures. Image processing was carried out in ImageJ. Pictures were transformed to 8 bits, scaled and corrected for uneven illumination using the background correction plugin from Terry $\mathrm{Wu}$ available at the ImageJ website ${ }^{2}$ with iteration of 3 and radius of 6 ptx. Each myenteric ganglion was marked and the mean gray value (integrated density/ $\mu \mathrm{m}^{2}$ ganglionic tissue) was determined. Eight ganglia per specimen were analyzed to calculate the mean gray value for each

\footnotetext{
${ }^{1}$ antibodies-online.com

${ }^{2}$ http://rsbweb.nih.gov/ij/plugins/
} 
specimen. Background correction was calculated using the formula: Corrected mean gray value $=$ mean gray value (target specimen) - mean gray value (blank specimen). Data were normalized to the experimental control and presented as fold increase of mean gray value.

\section{Statistical Analysis}

Comparison of mRNA expression levels of the NRG1 system and $\mathrm{nAchR}$ subunits between the control group and patients with $\mathrm{DD}$ were carried out by using unpaired student's $t$-test with Welch's correction for unequal variances. Fluorescence quantification data were analyzed by unpaired student's $t$-test; the effects of NRG1 and GDNF treatment on rat enteric nerve cell cultures regarding gene expression studies were analyzed by one-way-ANOVA followed by Bonferroni's multiple comparison test (Prism ${ }^{\mathrm{TM}}$, GraphPad, San Diego, CA, United States). Significant outlier was calculated with Grubb's test (Prism ${ }^{\mathrm{TM}}$, GraphPad, San Diego, CA, United States) and removed from the analysis. Differences were considered significant if $p<0.05$ and displayed as $*$, whereas $* *$ indicates $p<0.01$ vs. control and $* * *=p<0.001$ vs. control. Results are expressed as mean \pm SEM.

\section{RESULTS}

\section{Gene Expression Profiles of the NRG1 System and nAchR Subunits in Patients With DD and Controls}

To determine the gene regulation of the NRG1 system in patients with DD compared to controls, mRNA expression levels of NRG1 and its corresponding receptors ErbB2 und ErbB3 were monitored by qPCR. Analysis of the tunica muscularis revealed that NRG1 mRNA expression was significantly down-regulated in patients with $\mathrm{DD}$, as mRNA levels dropped to $37 \pm 8 \%$ of control values (Figure 1A). The NRG1 receptor ErbB3 also exhibited significant down-regulation with mRNA expression levels dropped to $45 \pm 10 \%$ of control values (Figure 1C). mRNA expression of ErbB2 also decreased in patients with DD, however, not at significant level (Figure 1B).

To analyze the regulation of $\mathrm{nAchR}$ subunits in patients with DD compared to controls, mRNA expression levels of nAchR subunits $\alpha 3, \alpha 5, \alpha 7, \beta 2$, and $\beta 4$ were investigated by qPCR in the tunica muscularis. Expression levels of $\alpha 3, \alpha 5$, and $\beta 4$ fall in the same range ( $\Delta C_{t}$ values), whereas subunits $\beta 2$ and $\alpha 7$ exhibited a 23.5 - and 2 -fold lower mRNA expression respectively compared to $\alpha 3, \alpha 5$, or $\beta 4$ subunits (data not shown). Whereas $\mathrm{nAchR}$ subunit $\beta 4$ expression was significantly down-regulated in patients with $\mathrm{DD}$, as mRNA levels dropped to $46 \% \pm 7$ of control values (Figure 2B), subunits $\beta 2$, $\alpha 3, \alpha 5$, and $\alpha 7$ showed no statistically significant alterations (Figures 2A,C-E).

Confirmatory to gene expression analysis in the tunica muscularis, site-specific gene expression in myenteric ganglia retrieved by $L M D$ revealed a significant down-regulation of NRG1, ErbB3 and nAchR $\beta 4$ in patients with DD by $26 \pm 6 \%$
(Figure 3A), $49 \pm 13 \%$ (Figure 3B), and $32 \pm 10 \%$ (Figure 3D) of control values respectively, whereas the expression of ErbB2 remained unaltered (Figure 3C).

\section{Immunohistochemistry of NRG1, ErbB2, ErbB3, and nAchR $\beta 4$ in Patients With DD and Controls}

NRG1, ErbB2, ErbB3, and nAchR $\beta 4$ immunoreactive signals were analyzed in patients with $\mathrm{DD}$ and compared to controls. While controls displayed strong NRG1 immunoreactive signals in both neurons and glial cells (Figure 4a), patients with DD showed considerably decreased and patchy immunoreactive signals in myenteric ganglia affecting both neuronal somata and the ganglionic neuropil (Figure 4b). ErbB2 immunoreactivity exhibited a punctuate staining pattern throughout the ganglia with most intensive immunoreactive signals in neuronal somata. No apparent differences between controls (Figure 4c) and patients with DD (Figure 4d) could be observed. In contrast, ErbB3 immunoreactive signals displayed a more homogeneous staining pattern decorating both neuronal somata and the ganglionic neuropil. Compared to controls (Figure 4e), patients with DD (Figure 4f) showed decreased immunoreactive signals for ErbB3, in particular in neuronal somata. nAchR $\beta 4$ exhibited homogenous immunopositive signals in neuronal somata and the ganglionic neuropil of controls (Figure $\mathbf{4 g}$ ). In patients with $\mathrm{DD}, \mathrm{nAchR} \beta 4$ immunoreactivity was considerably decreased (Figure $4 \mathbf{h}$ ).

The lightmicroscopical findings (Figure 4) were confirmed by subtle quantitative analysis of immunofluorescent signals (Figure 5): patients with DD showed a significant decrease in immunofluorescence intensity of NRG1 to $64 \pm 7 \%$ (Figures 5ac), ErbB3 to $50 \pm 10 \%$ (Figures 5 g,h), and nAchRb4 to $57 \pm 14 \%$ (Figures 5j-1) compared to controls, while immunofluorescence intensity of ErbB2 remained unaltered (Figures 5d-f).

\section{Effects of NRG1 and GDNF on nAchR $\alpha 3$, $\alpha 5, \alpha 7, \beta 2, \beta 4$ mRNA Expression in Cultured Enteric Neurons}

To estimate the impact of NRG1 on gene regulation of enteric $\mathrm{nAchR}$ subunits, mRNA expression of $\mathrm{nAchR}$ subunits $\alpha 3, \alpha 5$, $\alpha 7, \beta 2$, and $\beta 4$ was measured by RT-qPCR in rat enteric nerve cell cultures exposed to NRG1. Effects evoked by NRG1 were compared to those induced by the well characterized enteric neurotrophic factor GDNF. While treatment with NRG1 had no effect on gene expression of the $\mathrm{nAchR}$ subunit $\alpha 3, \alpha 5, \alpha 7$, and $\beta 2$ (Figures 6A,C-E), NRG1 (2 ng/mL) induced a twofold increase of mRNA expression levels of $n A c h R \beta 4$ (Figure 6B). Higher concentrations $(20 \mathrm{ng} / \mathrm{mL})$ showed not significant increase. GDNF had no effect on gene expression of all nAchR subunits measured (Figures 6A-E).

\section{DISCUSSION}

To our knowledge, this is the first study addressing deficits of the NRG1-system and altered nAchR subunit composition 

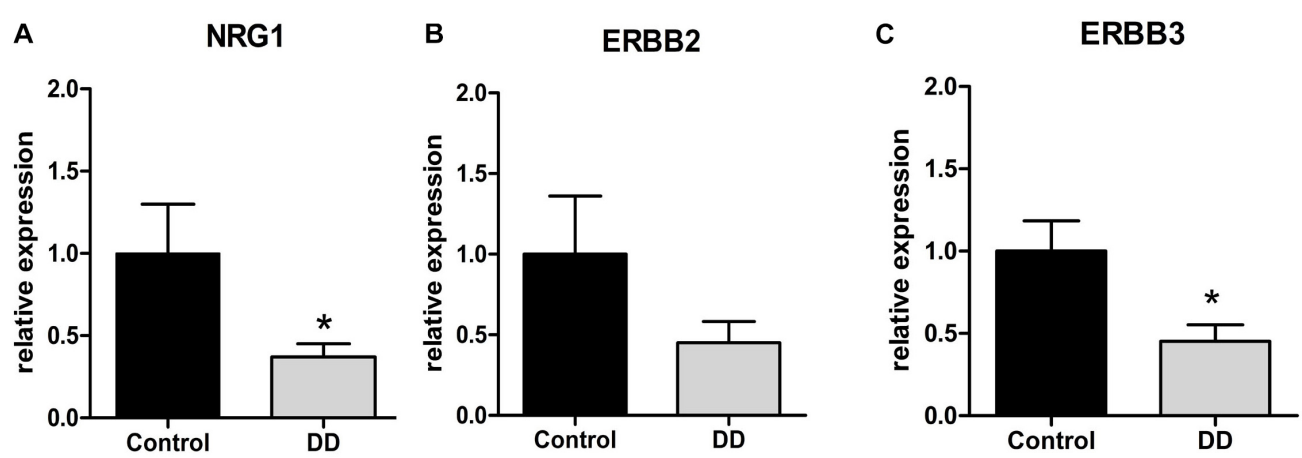

FIGURE 1 | mRNA expression of the NRG1 system in the tunica muscularis of controls and patients with DD. mRNA expression of NRG1 and ErbB3 is significantly down-regulated in patients with DD compared to controls $(\mathbf{A}, \mathbf{C})$, whereas the reduction of ErbB2 mRNA levels is not statistically significant (B). mRNA levels are determined by qPCR; expression of target genes is normalized to mRNA expression of the house-keeping gene HPRT. Data are shown as mean \pm SEM, $n=6-9$ per experimental group, ${ }^{*} p<0.05$ vs. control.

\section{A}

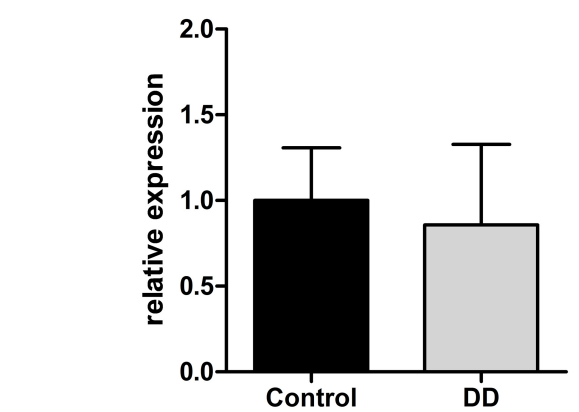

B

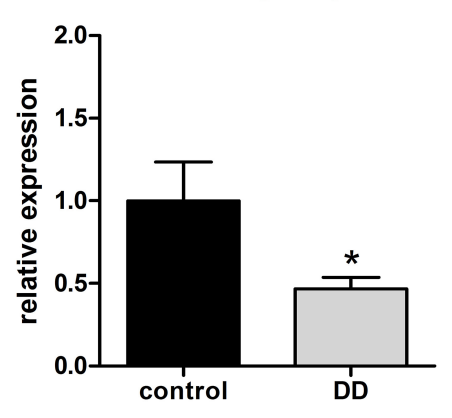

C

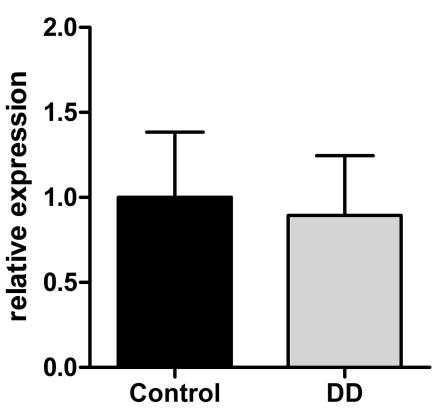

D

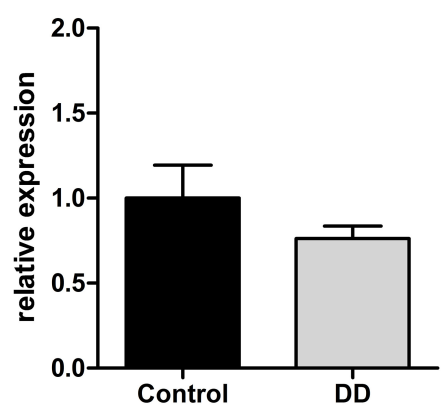

E

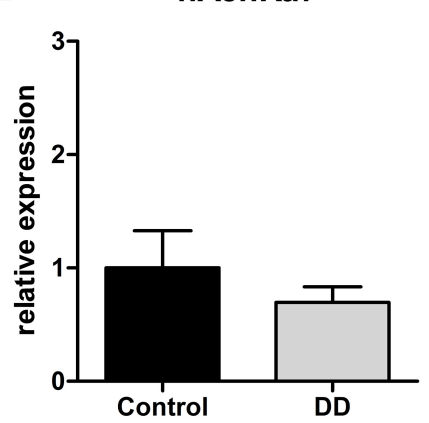

FIGURE 2 | mRNA expression of $n A$ chR subunits in the tunica muscularis of controls and patients with DD. mRNA expression of nAchRb4 is significantly down-regulated in patients with DD compared to controls (B), whereas mRNA expression levels of nAchR subunits b2, a3, a5, a7 levels showed no significant difference compared to controls (A,C,D,E). mRNA levels are determined by qPCR; expression of target genes is normalized to mRNA expression of the house-keeping gene HPRT. Data are shown as mean \pm SEM, $n=6-9$ per experimental group, ${ }^{*} p<0.05$ vs. control.

in patients with DD and investigating in vitro possible links between NRG1 and nAchR expression in the ENS. The study reveals three important findings: (1) The expression of NRG1 and its corresponding receptor ErbB3 is downregulated in enteric ganglia and intestinal musculature of patients with DD compared to controls; (2) Whereas the expression of $\mathrm{nAchR}$ subunit $\beta 4$ is decreased in patients with DD, other nAchR subunits remain unaltered; (3) NRG1 treatment promotes the mRNA expression of $\mathrm{nAchR}$ subunit $\mathrm{b} 4$ in enteric nerve cell cultures.

\section{Neurotrophic Factors and Their Corresponding Receptors in DD}

The pathogenesis of DD is considered to be multifactorial. Increasing evidence is given that $\mathrm{DD}$ is associated with an 


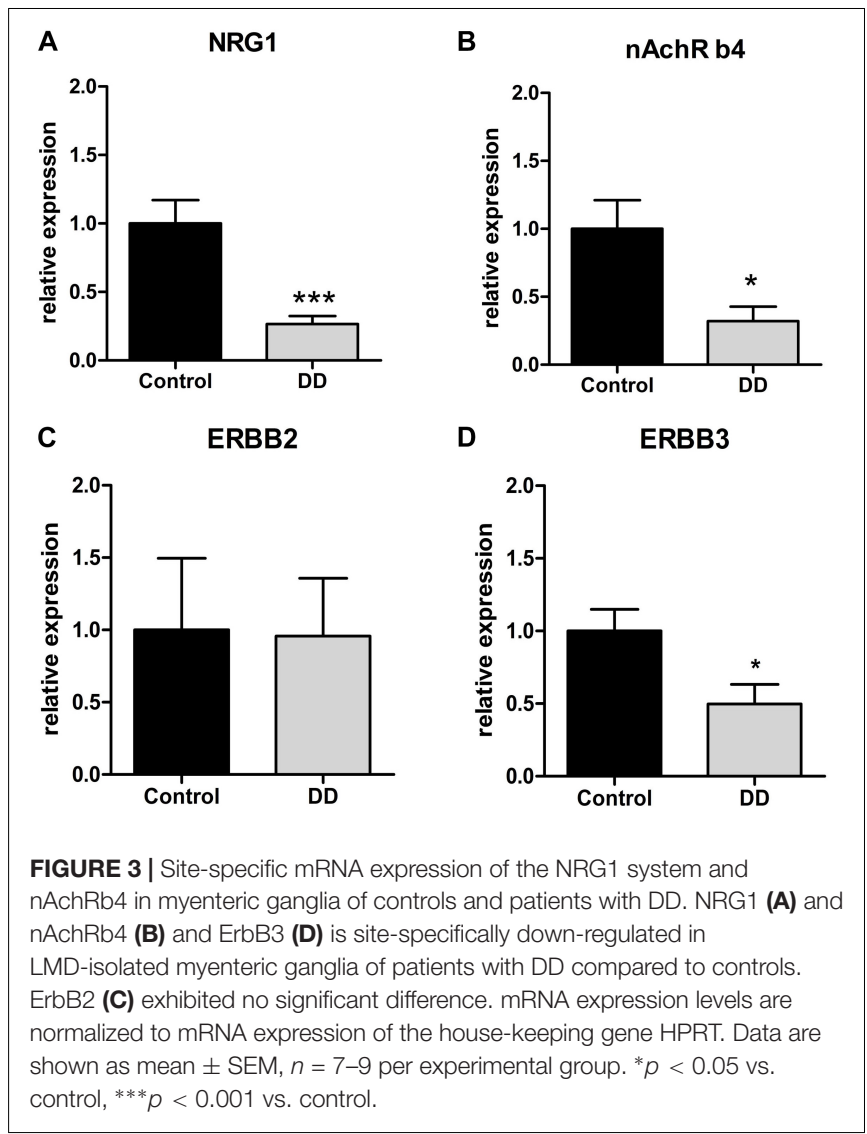

enteric neuropathy (Simpson et al., 2009) characterized by remodeling of nerve tissue (Golder et al., 2003), impaired intestinal motility patterns (Gallego et al., 2013), disturbed enteric neurotransmission (Espin et al., 2014), and a relative loss of enteric nerve cells (Iwase et al., 2005; Deduchovas et al., 2008; Wedel et al., 2010). It has been shown that GDNF, a potent growth factor for the ENS, is impaired not only in DD (Böttner et al., 2013), but also in asymptomatic diverticulosis suggesting that a deficient GDNF system may trigger the enteric nerve cell decrease in DD (Barrenschee et al., 2017).

Neuregulin 1 is also a known growth factor for the ENS. Whereas GDNF is mainly produced by the enteric musculature (Böttner et al., 2013), NRG1 is primarily expressed by enteric neuronal tissue (Barrenschee et al., 2015). Interestingly, GDNF stimulates the expression of NRG1 in motor neurons both in vitro and in vivo (Loeb and Fischbach, 1997; Loeb et al., 2002), and it is known that locally applied GDNF induces the release of NRG1 from neurons and their axons (Esper and Loeb, 2009). Although in a previous study on enteric nerve cell cultures, we could not confirm that GDNF enhances the gene expression of NRG1 (Barrenschee et al., 2015), it is suggestive that the decreased NRG1 protein expression observed in DD is a consequence of a deficient GDNF system previously described in DD.

Down-regulation of enteric neurotrophic factors and of their corresponding receptors in patients with DD was first
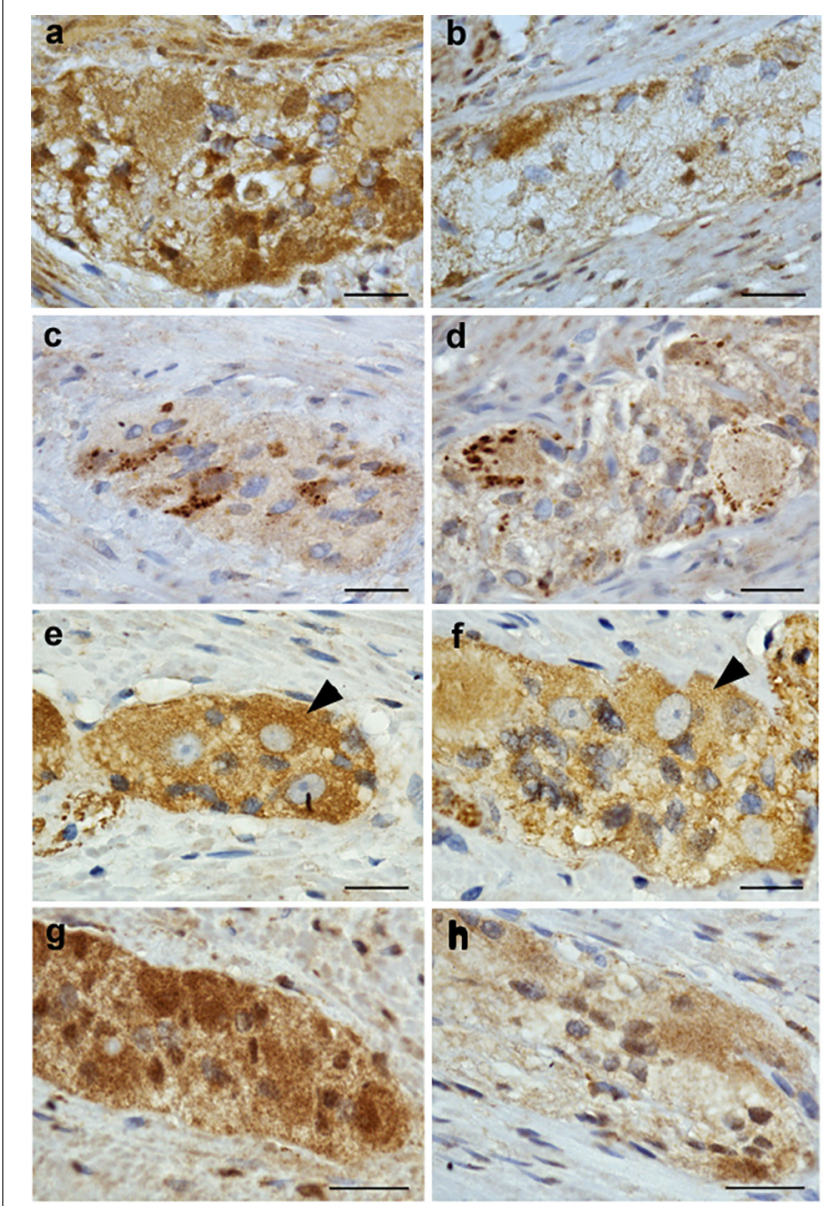

FIGURE 4 | NRG1, ErbB2, ErbB3, and nAchR $\beta 4$ immunoreactive signals in myenteric ganglia of controls and patients with DD. Robust NRG1 immunoreactive signals (brown colored deposits) detected in myenteric ganglia of controls (a) were considerably reduced in a patients with DD (b). The punctuate staining pattern of ErbB2 was equally discernible in both controls (c) and patients with DD (d), while ErbB3 immunoreactive signals were decreased in patients with DD (f) compared to controls (e), in particular regarding neuronal somata (arrowheads). $\mathrm{nAchR} \beta 4$ immunoreactive signals detected in myenteric ganglia of controls $\mathbf{( g )}$ are reduced in both neuronal somata and the neuropil of myenteric ganglia from patients with DD (h). Scale bars: $20 \mu \mathrm{m}$

investigated by Böttner et al. (2013), who observed decreased gene expression levels of the receptors for GDNF, RET, and GFR $\alpha 1$. A refined analysis revealed that the down-regulation of both receptors was most pronounced in myenteric ganglia (Barrenschee et al., 2017), thereby resembling the actual data on the NRG1-ErbB2/ErbB3 system in DD: The ErbB3 receptor predominantly expressed in enteric neuronal tissue is diminished in DD, whereas the ErbB2 receptor primarily expressed by enteric smooth muscle cells (Barrenschee et al., 2015) is not affected.

It is important to note that only a complex of both receptors can lead to phosphorylation and subsequent signaling in neuronal cells, since ErbB3 lacks kinase domain and ErbB2 lacks a ligand binding site (Holbro et al., 2003). Although 

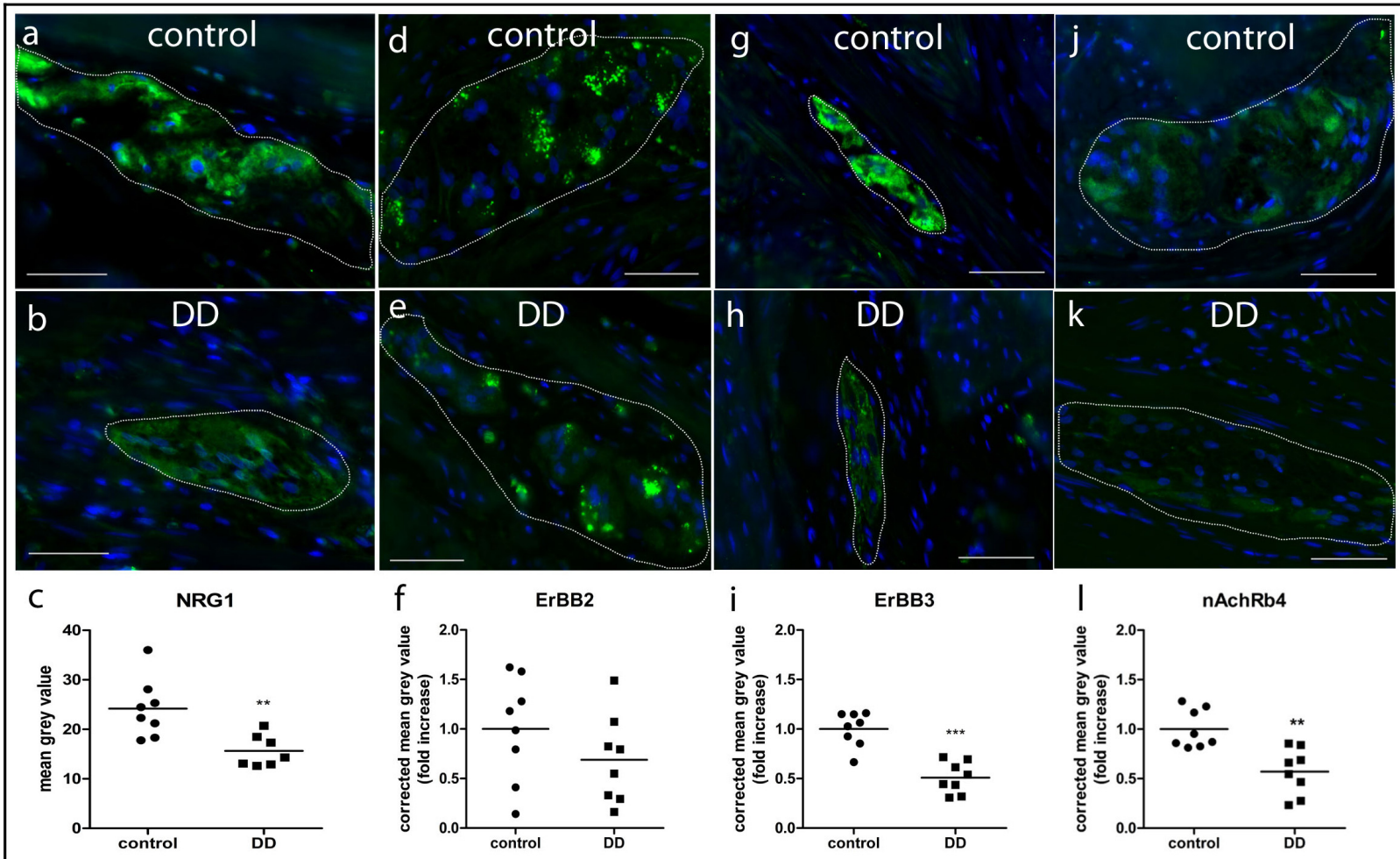

FIGURE 5 | Quantitative analysis of NRG1 (a-c), ErbB2 (d-f), ErbB3 (g-i), and nAchR (j-l) $\beta 4$ immunofluorescent signals in myenteric ganglia of controls and patients with DD. Immunofluorescent signals (green) in myenteric ganglia (marked by white line) of NRG1, ErbB3, and nAchR $\beta 4$ are significantly reduced in patients with DD compared to controls. Data are shown as corrected mean gray value normalized to controls presented as mean \pm SEM, $n=8$ per experimental group, $* * p<0.01$ vs. control, ${ }^{* * *} p<0.001$ vs. control. Nuclear stain with DAPI, bars $=50 \mu \mathrm{m}$.

not proven in detail by means of phosphorylation studies, the reduction of ErbB3 both at mRNA and protein level suggests a disturbed NRG1-ErbB2/ErbB3 signaling in enteric neuronal tissue. Thus, our findings indicate that the enteric neuropathy associated with DD is characterized by an altered receptor status of several enteric neurotrophic growth factors which in turn may lead to a disturbed signaling in enteric neuronal tissue.

In addition, the data suggest that the loss of GDNF not only leads to the down-regulation of its own receptors (Böttner et al., 2013), but may also cause down-regulation of NRG1 and ErbB3 in enteric neuronal tissue. A functional interaction between NRG1 and GDNF signaling was observed previously by Gui et al. (2013), who found a down-regulation of ErbB3 mRNA expression in response to GDNF stimulation. We could confirm a down-regulation of ErbB3 in enteric nerve cell cultures induced by GDNF and NRG1 (Barrenschee et al., 2015).

It is likely that deficiency of the GDNF system in patients with asymptomatic and symptomatic DD results in a loss of myenteric neurons which in turn leads to a loss of NRG1 expression. The decrease in NRG1 being a potent neurotrophic factor of the ENS and the concomitant down-regulation of its ErbB3 receptor further impairs the maintenance of enteric neuronal tissue and, thus, contributes to the enteric neuropathy in DD. Further studies are required to unravel whether a deficiency of the NRG1/ErbB2/ErbB3 system observed in DD may also occur in asymptomatic diverticulosis.

\section{Enteric Expression and Regulation of nAchR Subunits in DD}

Since $n$ AchRs are critical for gastrointestinal motility (Galligan and North, 2004) and DD is characterized by disturbed intestinal motility (Parks and Connell, 1969; Wedel et al., 2015), we investigated the mRNA expression of those nAchR subunits known to be present in the ENS: the ligand binding $n A c h R$ subunits $\alpha 3, \alpha 5, \alpha 7$ and the structural $\mathrm{nAchR}$ subunits $\beta 2, \beta 4$. While the structural $n A c h R$ subunit $\beta 4$ was down-regulated both at gene and protein level in patients with DD compared to controls, the other subunits remained unaffected.

In autonomic ganglia, the $\alpha 3 \beta 4$ subunit combination is considered to be the most prevalent combination (Park et al., 2006). This pattern seems to be conserved as Garza et al. (2009) observed in the ENS of neonatal rats by in situ hybridization that the majority of heteromeric nAchRs are also composed of $\alpha 3 \beta 4$ (with or without $\alpha 5$ ), while only a few consist of $\alpha 3$ and $\beta 2$ subunits. In line with Garza et al. (2009), we also found a lower $\beta 2$ subunit mRNA expression when compared to that of $\beta 4$. Noteworthy their semi-quantitative study on the expression 
A

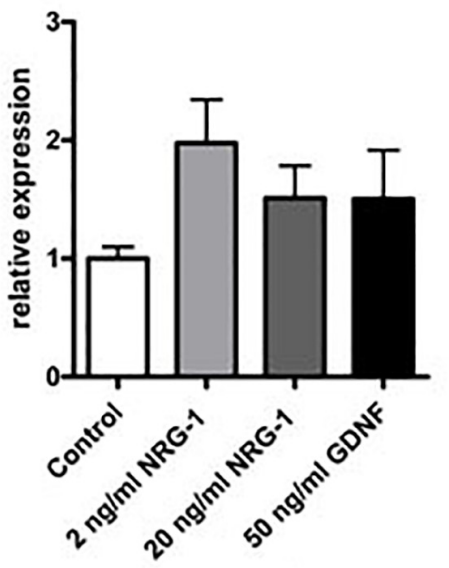

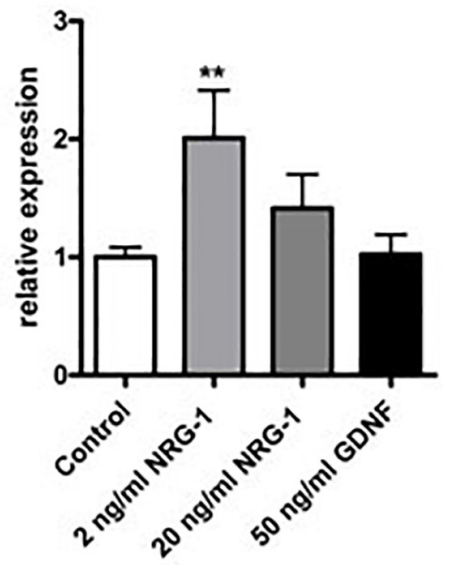

c

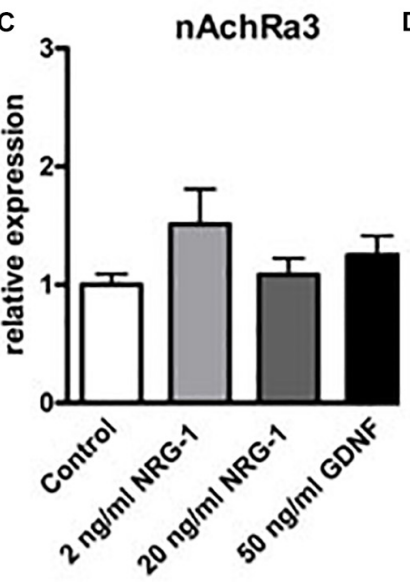

D

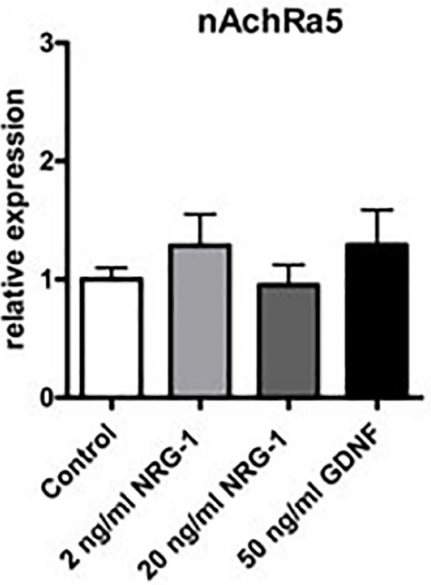

$E$

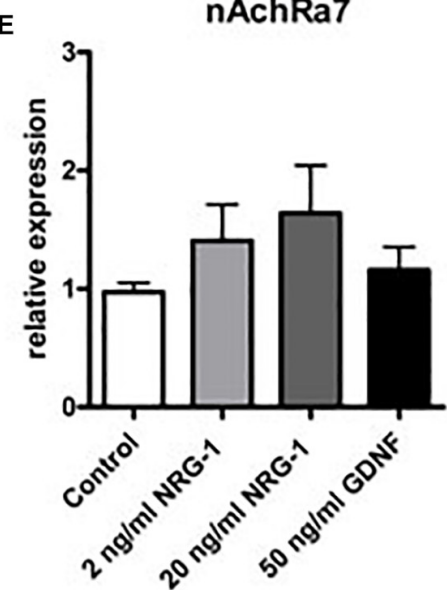

FIGURE 6 | mRNA expression of nAchR receptor subunits in enteric nerve cell cultures after exposure to NRG1 or GDNF. Treatment of cultured enteric nerve cells with NRG1 ( $2 \mathrm{ng} / \mathrm{mL}$ ) induced an increased mRNA expression of nAchR subunit $\beta 4$ (B), while gene expression levels of all other nAchR subunits (A,C-E) were not significantly altered. Treatment of GDNF did not show any significant effects on gene expression profiles of nAchR subunits. Expression levels of the target gene were normalized to expression of the house-keeping gene HPRT. Data are shown as mean $\pm \mathrm{SEM}, n=15-18$ per experimental group, ${ }^{* *} p<0.01$ vs. control.

of $\mathrm{nAchR}$ subunits $\alpha 3, \alpha 5, \alpha 7, \beta 2, \beta 4$ in the large intestine of the rat matched with our observations.

We found a diminished myenteric $\beta 4$ subunit expression in patients with DD when compared to control. Since it is known that deficiency of the $\mathrm{nAchR}$ subunit $\beta 4$ results in reduced ileal contractile response to nicotinic agonists in mice (Wang et al., 2003), a dysfunctional $n A c h R$ receptor may contribute to the impairment of gastrointestinal motility observed in DD. A compensation of structural subunit $\beta 4$ to $\beta 2$ with altered activation kinetics or reduced sensitivity to agonists and antagonist previously described in nerve cell cultures (Nelson et al., 2001; Wang et al., 2003) is rather unlikely, since there is no significant change in the expression of the structural subunit $\beta 2$ in DD.

In our cell culture experiments, we observed a significant upregulation of $\mathrm{nAchR} \beta 4$ upon NRG1 stimulation, whereas other subunits remained unaffected. This finding is similar to that from Kim et al. (2013), who reported that NRG1 up-regulated the expression of the $\mathrm{nAchR} \alpha 3$ and $\beta 4$ subunits in both sympathetic and parasympathetic major pelvic ganglion neurons from adult rats. In addition, NRG1 was shown to be involved in the formation of nicotinic synapses by increasing the expression of $\mathrm{nAchR}$ subunits $\alpha 3, \alpha 5, \alpha 7$, and $\beta 4$ in embryonic chick sympathetic neurons (Yang et al., 1998). However, we did not found any other receptor subunits regulated by NRG1, suggesting, that in the human ENS only the $\beta 4$ subunit is regulated by this growth factor.

\section{CONCLUSION}

Taken together, our results give first evidence that DD is associated with a decrease of the neurotrophic factor NRG1 and its corresponding receptor ErbB3. The in vitro data illustrate that NRG1 promotes the expression of the nAchR $\beta 4$ subunit, that is also down-regulated in DD suggesting a 
link between NRG1 and nAchR $\beta 4$ expression. Thus, lack of NRG1 in DD may lead to a decrease of $n A c h R \beta 4$ and subsequently a reduced receptor configuration which in turn may contribute to the impaired intestinal motility observed in DD. Obviously, the enteric neuropathy previously described in DD also involves deficiency of several enteric neurotrophic factors and of neurotransmitter receptors.

\section{DATA AVAILABILITY STATEMENT}

The raw data supporting the conclusions of this article will be made available by the authors, without undue reservation, to any qualified researcher.

\section{ETHICS STATEMENT}

The studies involving human participants were reviewed and approved by the Local Ethics Committee of the Faculty of Medicine, Christian-Albrechts University of Kiel, Germany. The patients/participants provided their written informed consent to participate in this study. The animal study was reviewed and approved by the Local Ethics Committee of the Faculty of Medicine, Christian-Albrechts University of Kiel.

\section{REFERENCES}

Albuquerque, E. X., Pereira, E. F., Alkondon, M., and Rogers, S. W. (2009). Mammalian nicotinic acetylcholine receptors: from structure to function. Physiol. Rev. 89, 73-120. doi: 10.1152/physrev.00015.2008

Barrenschee, M., Lange, C., Cossais, F., Egberts, J. H., Becker, T., Wedel, T., et al. (2015). Expression and function of Neuregulin 1 and its signaling system ERBB2/3 in the enteric nervous system. Front. Cell. Neurosci. 9:360. doi: 10. $3389 /$ fncel.2015.00360

Barrenschee, M., Wedel, T., Lange, C., Hohmeier, I., Cossais, F., Ebsen, M., et al. (2017). No neuronal loss, but alterations of the GDNF system in asymptomatic diverticulosis. PLoS One 12:e0171416. doi: 10.1371/journal.pone.0171416

Bassotti, G., Battaglia, E., Spinozzi, F., Pelli, M. A., and Tonini, M. (2001). Twentyfour hour recordings of colonic motility in patients with diverticular disease: evidence for abnormal motility and propulsive activity. Dis. Colon. Rectum 44, 1814-1820. doi: 10.1007/bf02234460

Böttner, M., Bar, F., Von Koschitzky, H., Tafazzoli, K., Roblick, U. J., Bruch, H. P., et al. (2010). Laser microdissection as a new tool to investigate site-specific gene expression in enteric ganglia of the human intestine. Neurogastroenterol. Motil. 22, 168-172,e152. doi: 10.1111/j.1365-2982.2009.01424.x

Böttner, M., Barrenschee, M., Hellwig, I., Harde, J., Egberts, J. H., Becker, T., et al. (2013). The GDNF system is altered in diverticular disease - implications for pathogenesis. PLoS One 8:e66290. doi: 10.1371/journal.pone.0066290

Böttner, M., and Wedel, T. (2012). Abnormalities of neuromuscular anatomy in diverticular disease. Dig. Dis. 30, 19-23. doi: 10.1159/000335699

Britsch, S., Li, L., Kirchhoff, S., Theuring, F., Brinkmann, V., Birchmeier, C., et al. (1998). The ErbB2 and ErbB3 receptors and their ligand, neuregulin-1, are essential for development of the sympathetic nervous system. Genes Dev. 12, 1825-1836. doi: 10.1101/gad.12.12.1825

Crone, S. A., Negro, A., Trumpp, A., Giovannini, M., and Lee, K. F. (2003). Colonic epithelial expression of ErbB2 is required for postnatal maintenance of the enteric nervous system. Neuron 37, 29-40. doi: 10.1016/s0896-6273(02) 01128-5

Dani, J. A., and Bertrand, D. (2007). Nicotinic acetylcholine receptors and nicotinic cholinergic mechanisms of the central nervous system. Annu. Rev. Pharmacol. Toxicol. 47, 699-729. doi: 10.1146/annurev.pharmtox.47.120505.105214

\section{AUTHOR CONTRIBUTIONS}

$\mathrm{MBa}$ was responsible for study design, acquisition and interpretation of data, data analysis, and writing of the manuscript. FC was responsible for acquisition and interpretation of data, and critically revising of the manuscript. $\mathrm{J}-\mathrm{HE}$ and $\mathrm{TB}$ contributed to the acquisition of the human material. TW and MBö critically revised the manuscript and wrote the grants financing the study.

\section{FUNDING}

This study was supported by research grants from the German Research Foundation (DFG, WE 2366/4-3 and WE 2366/5-1) and the Faculty of Medicine, Christian-Albrechts University of Kiel (F347022).

\section{ACKNOWLEDGMENTS}

The authors thank Karin Stengel, Inka Geurink, Miriam Lemmer, and Bettina Facompré (Institute of Anatomy, Christian-Albrechts University of Kiel) for their excellent technical assistance.

Deduchovas, O., Saladzinskas, Z., Tamelis, A., Pavalkis, D., Pauziene, N., and Pauza, D. H. (2008). Morphologic pattern of myenteric neural plexus in colonic diverticular disease. A whole-mount study employing histochemical staining for acetylcholinesterase. Ann. Anat. 190, 525-530. doi: 10.1016/j.aanat.2008. 09.002

Erickson, S. L., O’Shea, K. S., Ghaboosi, N., Loverro, L., Frantz, G., Bauer, M., et al. (1997). ErbB3 is required for normal cerebellar and cardiac development: a comparison with ErbB2-and heregulin-deficient mice. Development 124, 4999-5011.

Esper, R. M., and Loeb, J. A. (2009). Neurotrophins induce neuregulin release through protein kinase Cdelta activation. J. Biol. Chem. 284, 26251-26260. doi: 10.1074/jbc.M109.002915

Espin, F., Rofes, L., Ortega, O., Clave, P., and Gallego, D. (2014). Nitrergic neuro-muscular transmission is up-regulated in patients with diverticulosis. Neurogastroenterol. Motil. 26, 1458-1468. doi: 10.1111/nmo.12407

Falls, D. L. (2003). Neuregulins and the neuromuscular system: 10 years of answers and questions. J. Neurocytol. 32, 619-647. doi: 10.1023/B:NEUR.0000020614. 83883.be

Falls, D. L., Rosen, K. M., Corfas, G., Lane, W. S., and Fischbach, G. D. (1993). ARIA, a protein that stimulates acetylcholine receptor synthesis, is a member of the neu ligand family. Cell 72, 801-815.

Gallego, D., Espin, F., Mikulka, J., Smirg, O., Gil, V., Faundez-Zanuy, M., et al. (2013). In vitro motor patterns and electrophysiological changes in patients with colonic diverticular disease. Int. J. Colorect. Dis. 28, 1413-1422. doi: 10. 1007/s00384-013-1716-7

Galligan, J. J., and North, R. A. (2004). Pharmacology and function of nicotinic acetylcholine and P2X receptors in the enteric nervous system. Neurogastroenterol. Motil. 16(Suppl. 1), 64-70. doi: 10.1111/j.1743-3150.2004. 00478.x

Garratt, A. N., Britsch, S., and Birchmeier, C. (2000). Neuregulin, a factor with many functions in the life of a schwann cell. BioEssays 22, 987-996. doi: 10. 1002/1521-1878(200011)22:11<987:AID-BIES5<3.0.CO;2-5

Garza, A., Huang, L. Z., Son, J. H., and Winzer-Serhan, U. H. (2009). Expression of nicotinic acetylcholine receptors and subunit messenger RNAs in the enteric nervous system of the neonatal rat. Neuroscience 158, 1521-1529. doi: 10.1016/ j.neuroscience.2008.11.027 
Golder, M., Burleigh, D. E., Belai, A., Ghali, L., Ashby, D., Lunniss, P. J., et al. (2003). Smooth muscle cholinergic denervation hypersensitivity in diverticular disease. Lancet 361, 1945-1951. doi: 10.1016/S0140-6736(03)13583-0

Grundy, D., and Schemann, M. (2006). Enteric nervous system. Curr. Opin. Gastroenterol. 22, 102-110. doi: 10.1097/01.mog.0000208459.46395.16

Gui, H., Tang, W. K., So, M. T., Proitsi, P., Sham, P. C., Tam, P. K., et al. (2013). RET and NRG1 interplay in Hirschsprung disease. Hum. Genet. 132, 591-600. doi: 10.1007/s00439-013-1272-9

Holbro, T., Civenni, G., and Hynes, N. E. (2003). The ErbB receptors and their role in cancer progression. Exp. Cell Res. 284, 99-110. doi: 10.1016/s0014-4827(02) 00099- $\mathrm{x}$

Iwase, H., Sadahiro, S., Mukoyama, S., Makuuchi, H., and Yasuda, M. (2005). Morphology of myenteric plexuses in the human large intestine: comparison between large intestines with and without colonic diverticula. J. Clin. Gastroenterol. 39, 674-678. doi: 10.1097/01.mcg.0000173856.84814.37

Jun, S., and Stollman, N. (2002). Epidemiology of diverticular disease. Best Pract. Res. Clin. Gastroenterol. 16, 529-542.

Kim, H. G., Lee, C. K., Cho, S. M., Whang, K., Cha, B. H., Shin, J. H., et al. (2013). Neuregulin 1 up-regulates the expression of nicotinic acetylcholine receptors through the ErbB2/ErbB3-PI3K-MAPK signaling cascade in adult autonomic ganglion neurons. J. Neurochem. 124, 502-513. doi: 10.1111/jnc.12109

Knowles, C. H., De Giorgio, R., Kapur, R. P., Bruder, E., Farrugia, G., Geboes, K., et al. (2010). The London classification of gastrointestinal neuromuscular pathology: report on behalf of the Gastro 2009 International Working Group. Gut 59, 882-887. doi: 10.1136/gut.2009.200444

Loeb, J. A., and Fischbach, G. D. (1997). Neurotrophic factors increase neuregulin expression in embryonic ventral spinal cord neurons. J. Neurosci. 17, 14161424. doi: 10.1523/jneurosci.17-04-01416.1997

Loeb, J. A., Hmadcha, A., Fischbach, G. D., Land, S. J., and Zakarian, V. L. (2002). Neuregulin expression at neuromuscular synapses is modulated by synaptic activity and neurotrophic factors. J. Neurosci. 22, 2206-2214. doi: 10.1523/ jneurosci.22-06-02206.2002

Mandl, P., and Kiss, J. P. (2007). Role of presynaptic nicotinic acetylcholine receptors in the regulation of gastrointestinal motility. Brain Res. Bull. 72, 194-200. doi: 10.1016/j.brainresbull.2007.02.005

Mao, D., Yasuda, R. P., Fan, H., Wolfe, B. B., and Kellar, K. J. (2006). Heterogeneity of nicotinic cholinergic receptors in rat superior cervical and nodose Ganglia. Mol. Pharmacol. 70, 1693-1699. doi: 10.1124/mol.106.027458

Martinou, J. C., Falls, D. L., Fischbach, G. D., and Merlie, J. P. (1991). Acetylcholine receptor-inducing activity stimulates expression of the epsilon-subunit gene of the muscle acetylcholine receptor. Proc. Natl. Acad. Sci. U.S.A. 88, 7669-7673. doi: 10.1073/pnas.88.17.7669

Mei, L., and Nave, K. A. (2014). Neuregulin-ERBB signaling in the nervous system and neuropsychiatric diseases. Neuron 83, 27-49. doi: 10.1016/j.neuron.2014. 06.007

Nelson, M. E., Wang, F., Kuryatov, A., Choi, C. H., Gerzanich, V., and Lindstrom, J. (2001). Functional properties of human nicotinic AChRs expressed by IMR32 neuroblastoma cells resemble those of alpha3beta4 AChRs expressed in permanently transfected HEK cells. J. Gen. Physiol. 118, 563-582. doi: 10.1085/ jgp.118.5.563

Obaid, A. L., Nelson, M. E., Lindstrom, J., and Salzberg, B. M. (2005). Optical studies of nicotinic acetylcholine receptor subtypes in the guinea-pig enteric nervous system. J. Exp. Biol. 208(Pt 15), 2981-3001. doi: 10.1242/jeb. 01732

Park, K. S., Cha, S. K., Kim, M. J., Kim, D. R., Jeong, S. W., Lee, J. W., et al. (2006). An alpha3beta4 subunit combination acts as a major functional nicotinic acetylcholine receptor in male rat pelvic ganglion neurons. Pflugers Archiv 452, 775-783. doi: 10.1007/s00424-006-0086-1

Parks, T. G., and Connell, A. M. (1969). Motility studies in diverticular disease of the colon. Gut 10, 534-542. doi: 10.1136/gut.10.7.534

Riethmacher, D., Sonnenberg-Riethmacher, E., Brinkmann, V., Yamaai, T., Lewin, G. R., and Birchmeier, C. (1997). Severe neuropathies in mice with targeted mutations in the ErbB3 receptor. Nature 389, 725-730. doi: 10.1038/39593

Sandler, R. S., Everhart, J. E., Donowitz, M., Adams, E., Cronin, K., Goodman, C., et al. (2002). The burden of selected digestive diseases in the United States. Gastroenterology 122, 1500-1511. doi: 10.1053/gast.2002.32978

Sandrock, AW Jr, Dryer, S. E., Rosen, K. M., Gozani, S. N., Kramer, R., Theill, L. E., et al. (1997). Maintenance of acetylcholine receptor number by neuregulins at the neuromuscular junction in vivo. Science 276, 599-603. doi: 10.1126/science. 276.5312 .599

Sargent, P. B. (1993). The diversity of neuronal nicotinic acetylcholine receptors. Annu. Rev. Neurosci. 16, 403-443. doi: 10.1146/annurev.ne.16.030193.002155

Schäfer, K. H., Saffrey, M. J., Burnstock, G., and Mestres-Ventura, P. (1997). A new method for the isolation of myenteric plexus from the newborn rat gastrointestinal tract. Brain Res. Brain Res. Protoc. 1, 109-113. doi: 10.1016/ s1385-299x(96)00017-7

Simpson, J., and Spiller, R. (2002). Colonic diverticular disease. BMJ Clin. Evid. 2007:0405.

Simpson, J., Sundler, F., Humes, D. J., Jenkins, D., Scholefield, J. H., and Spiller, R. C. (2009). Post inflammatory damage to the enteric nervous system in diverticular disease and its relationship to symptoms. Neurogastroenterol. Motil. 21:847-e58. doi: 10.1111/j.1365-2982.2009.01308.x

Strate, L. L., Liu, Y. L., Aldoori, W. H., Syngal, S., and Giovannucci, E. L. (2009). Obesity increases the risks of diverticulitis and diverticular bleeding. Gastroenterology 136, 115.e11-122.e11. doi: 10.1053/j.gastro.2008.09.025

Wang, N., Orr-Urtreger, A., Chapman, J., Rabinowitz, R., and Korczyn, A. D. (2003). Deficiency of nicotinic acetylcholine receptor beta 4 subunit causes autonomic cardiac and intestinal dysfunction. Mol. Pharmacol. 63, 574-580. doi: $10.1124 / \mathrm{mol} .63 .3 .574$

Wedel, T., Barrenschee, M., Lange, C., Cossais, F., and Böttner, M. (2015). Morphologic basis for developing diverticular disease, diverticulitis, and diverticular bleeding. Viszeralmedizin 31, 76-82. doi: 10.1159/000381431

Wedel, T., Busing, V., Heinrichs, G., Nohroudi, K., Bruch, H. P., Roblick, U. J., et al. (2010). Diverticular disease is associated with an enteric neuropathy as revealed by morphometric analysis. Neurogastroenterol. Motil. 22:e00493-04. doi: 10.1111/j.1365-2982.2009.01445.x

Yang, X., Kuo, Y., Devay, P., Yu, C., and Role, L. (1998). A cysteine-rich isoform of neuregulin controls the level of expression of neuronal nicotinic receptor channels during synaptogenesis. Neuron 20, 255-270. doi: 10.1016/s08966273(00)80454-7

Conflict of Interest: The authors declare that the research was conducted in the absence of any commercial or financial relationships that could be construed as a potential conflict of interest.

Copyright (c) 2019 Barrenschee, Cossais, Böttner, Egberts, Becker and Wedel. This is an open-access article distributed under the terms of the Creative Commons Attribution License (CC BY). The use, distribution or reproduction in other forums is permitted, provided the original author(s) and the copyright owner(s) are credited and that the original publication in this journal is cited, in accordance with accepted academic practice. No use, distribution or reproduction is permitted which does not comply with these terms. 